\title{
Full and empty nest syndromes in women in the climacteric period
}

\author{
Ana Carolina Gonçalves de Abreu ${ }^{1}$ (D), Mayara Souza Alves² (D), Lea Tami Suzuki Zuchelo² (D), \\ Sueli Vitorino dos Santos ${ }^{3}$ (D), Priscilla Rayanne e Silva Noll ${ }^{2}$ (D), Edmund Chada Baracat ${ }^{2}$ (D), \\ José Maria Soares Júnior ${ }^{2}$ (D) Isabel Cristina Esposito Sorpreso²*
}

\section{INTRODUCTION}

The empty nest syndrome (ENS) was cited as menopausal symptoms related to mood changes and characterized when the last or only child leaves the parental home, as well as in case of death of spouses/partners ${ }^{1}$. Others describe the ENS as a presence of loneliness, aggravated by emotional and psychosocial symptoms, depressive mood, and emotional lability prevalent in the climacteric period ${ }^{1-3}$.

The social changes and family configuration bring a new way of experiencing and dealing with the symptoms of menopause 4,5 . The phenomenon known as "Full Nest Syndrome" (FNS) is a recent term in the literature characterized as a change in family coexistence, with the permanence of adult children in their parents' house ${ }^{4}$. It denotes a change in the role of women in the family nucleus regarding socioeconomic attributions, educational, and reproductive autonomy.

Both syndromes can be identified in women's health care in the climacteric period. Factors associated with the presence of ENS and FNS should have a differential investigation and analysis instead of being automatically attributed to menopause, as they have different definitions and approaches in health care. Besides, the authors highlighted the scarcity of studies on the theme and the impact of these two syndromes on mood symptoms during the climacteric period ${ }^{5-7}$.

Thus, analyzing the psychosocial factors of FNS and ENS reveals, through the scientific literature, the specificities of each syndrome, which can contribute to a better quality of care and different and effective intervention actions. The purpose of this review was to analyze, through a systematic review, factors related to FNS and ENS in the climacteric period.

\section{METHODS}

This is a systematic review based on PRISMA ${ }^{8}$ performed by the Climacteric Sector of the Gynecology Division of the Hospital das Clínicas at Medicine School of the São Paulo University (HC/FMUSP), registered in PROSPERO in February 2019 (ID number: CRD42019121218).

\section{Research strategy}

This review was based on a systematic research conducted on January 2020 using PubMed, Web of Science, Embase, and PsycINFO databases and followed the PICO ( $\mathrm{P}=$ Population, $\mathrm{I}=$ Intervention, $\mathrm{C}=$ comparison, and $\mathrm{O}=$ outcome) strategy, in order to obtain the keywords at Medical Subject Headings $(\mathrm{MeSH})$ and Embase subject headings (Emtree) - empty nest, full nest, menopause, climacteric, premenopause, and postmenopause (Appendix 1).

\section{Inclusion criteria}

Studies published in English were selected if they met the following criteria:

(1) studies related to women in the climacteric period and

(2) that approach FNS and ENS.

There was no restriction on sample size or publication date.

\section{Exclusion criteria}

The articles were excluded if:

(1) they were not data-based (i.e., books, theoretical articles, or minor revisions),

(2) had population not clearly identified in the climacteric period, and

\footnotetext{
${ }^{1}$ Faculdade Santa Maria - Cajazeiras (PB), Brazil.

¿Universidade de São Paulo, Faculdade de Medicina, Departamento de Obstetrícia e Ginecologia - São Paulo (SP), Brazil.

3Universidade Mogi das Cruzes - São Paulo (SP), Brazil.

*Corresponding author: icesorpreso@usp.br

Conflicts of interest: the authors declare there are no conflicts of interest. Funding: none.

Received on August 24, 2021. Accepted on August 27, 2021.
} 
(3) superficially addressed the FNS and ENS, describing only the prevalence of the syndromes, without characterizing the symptoms.

\section{Search strategy}

Three stages were used to select the articles. The first stage was to screen all titles; the second stage was to exclude articles using the abstract; and the third stage was to analyze the entire text, searching for eligible manuscripts. All stages were based on the selection criteria explained above.

To increase the reliability of the analysis and minimize possible biases, all the search and selection phases were independently reviewed by two researchers (ACGA and MSA) who, after reading all articles, entered a consensus to establish which articles met the inclusion criteria. In cases in which there was disagreement over the selection of studies among the investigators, a third reviewer (LTSZ) was consulted.

\section{Assessment of study quality}

Two reviewers independently assessed the risk of bias of each included study and discussed their assessments to achieve consensus. Score disagreements were resolved by consensus, and a final agreed-upon rating was assigned to each study.

Since both quantitative and qualitative studies were considered in this study, appropriate tools were used for each one.

For quantitative studies, the Newcastle-Ottawa Scale (NOS) adapted for cross-sectional studies was used to assess the quality of research"10. The NOS has a "star system" in which a study is judged on three dimensions, namely, selection (five stars), comparability (two stars), and outcomes (three stars), indicating the quality of the study. The range of stars in the NOS comprises 0-10 stars.

For qualitative studies, the consolidated criteria for reporting qualitative research (CORE-Q) was used to assess the quality of research ${ }^{11}$. The CORE-Q is a 32-item checklist for interviews and focus groups by three domains, namely, "research and reflexivity team" (8 items), "of the study" (15 items), and "analysis and findings" ( 9 items). The nonavailability information needed to answer CORE-Q questions was filled in as no information in the article.

\section{RESULTS}

The search of the databases resulted in 102 papers. Duplicate articles were excluded using the Microsoft Excel "Duplicates" tool and manually, totalizing 39 articles. After screening for title and abstract, 29 articles were excluded as they were not related to the theme and 7 articles were not available for free. The 26 remaining articles were read in their entirety, and 18 articles did not meet the inclusion criteria; thus, 8 articles were selected to compose this systematic review (Figure 1).

In Table 1, eight eligible articles are presented and classified according to the score obtained in the NOS and COREQ application. The articles that made a qualitative analysis of the data were classified as moderate according to the COREQ evaluation, obtaining a score between 16 and 19 out of a total of 32 points $^{12-15}$. The articles that made a quantitative analysis of the data were classified with 7-9 out of 10 stars $^{16-19}$.

Also, in Table 1, the aim of this study, sample, and main results related to ENS and/or FNS are presented. Eight articles were published between 1984 and 2013 and were related to the ENS and women in the climacteric period. Only one article covered both FNS and ENS ${ }^{17}$. The studies were conducted in Mexico, Japan, Malaysia, USA, Uruguay, and Australia, and the number of participants included varied from 40 to 386 , totalizing 1525 women in the climacteric period ${ }^{12-19}$.

The study design of the articles was cross-sectional, with only one article being a longitudinal study with a follow-up of 8 years ${ }^{12-16,18,19}$.

In Table 2, we presented the events and situations that trigger the ENS and/or FNS and changes related to the syndromes. Two articles did not mention any changes related to ENS and/or FNS ${ }^{18,19}$.

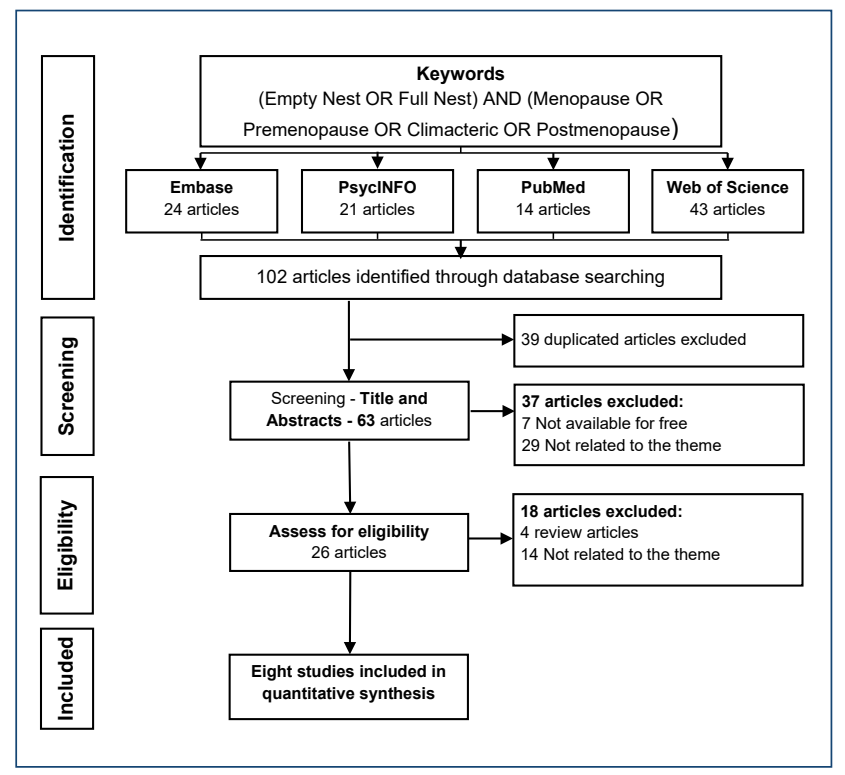

Figure 1. Literature review citation selection flowchart (Adapted from Moher et al. ${ }^{8}$ ). 


\begin{tabular}{|c|c|c|c|c|}
\hline $\begin{array}{l}\frac{\vec{t}}{\bar{T}} \\
\frac{\mathrm{\sigma}}{\vec{J}}\end{array}$ & 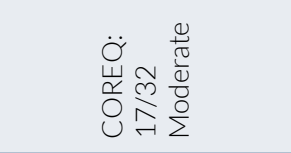 & $\begin{array}{l}\stackrel{0}{1} \\
\stackrel{1}{0} \\
\ddot{0} \\
\stackrel{0}{Z}\end{array}$ & 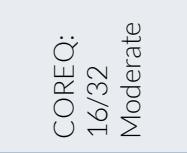 & 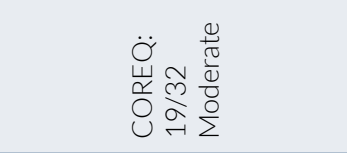 \\
\hline 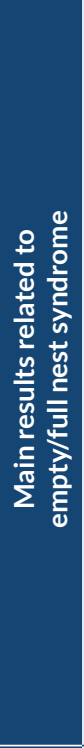 & 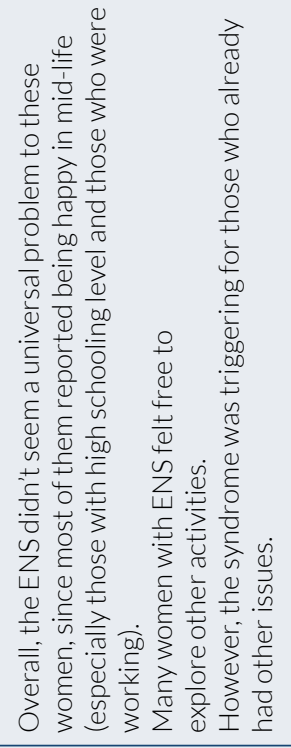 & 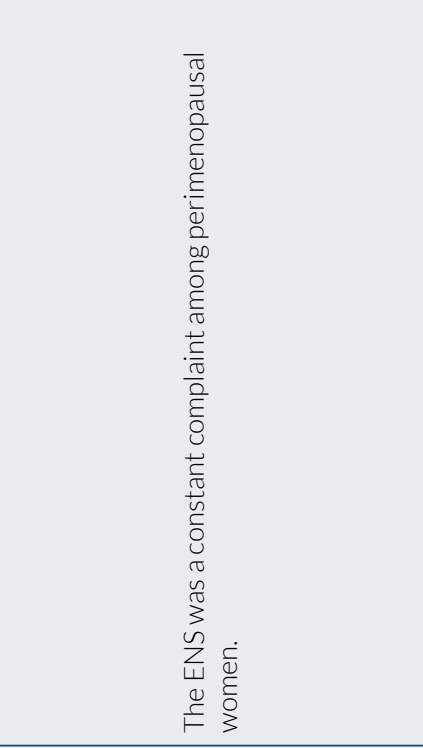 & 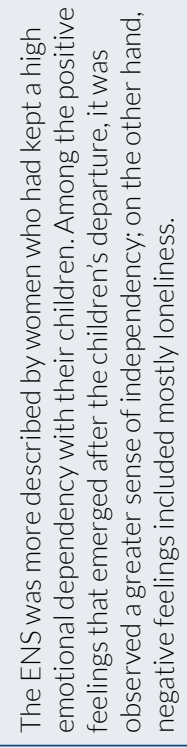 & 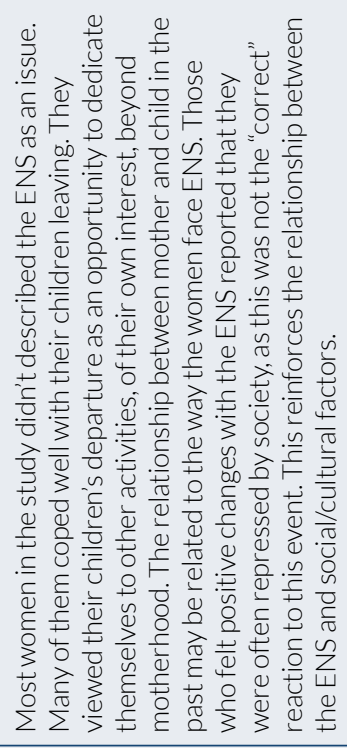 \\
\hline 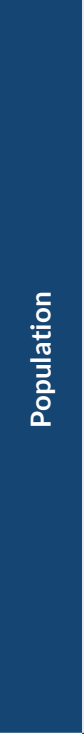 & 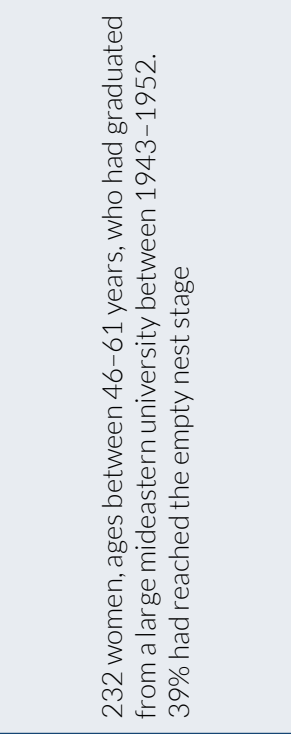 & 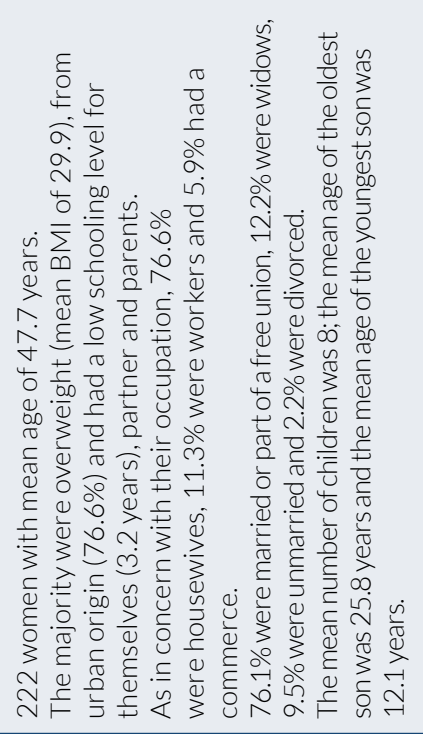 & 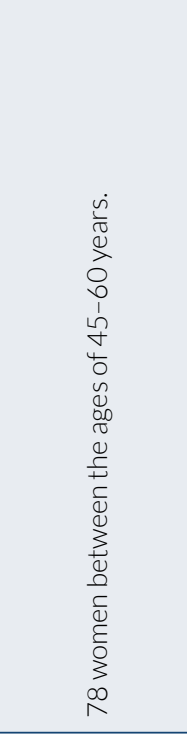 & 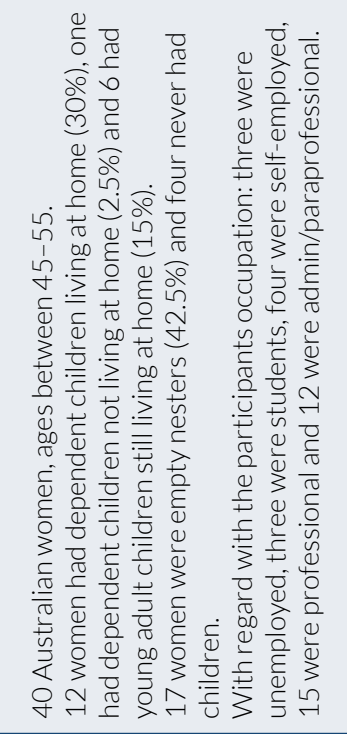 \\
\hline 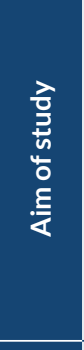 & 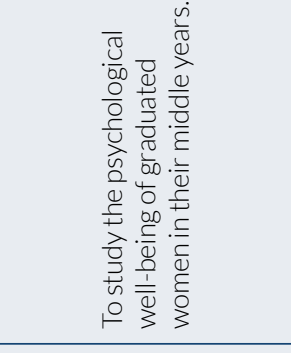 & 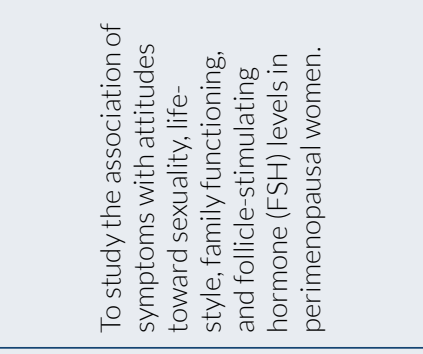 & 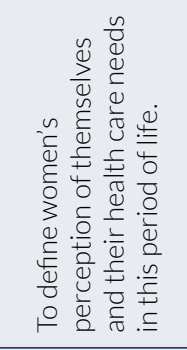 & 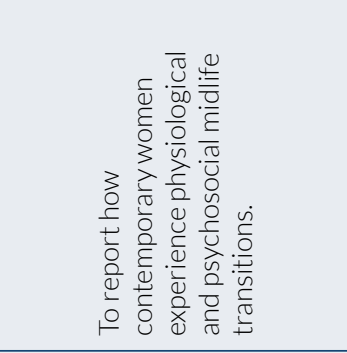 \\
\hline 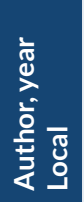 & 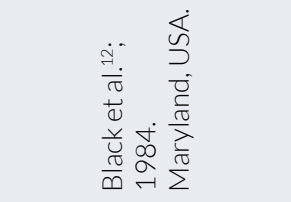 & 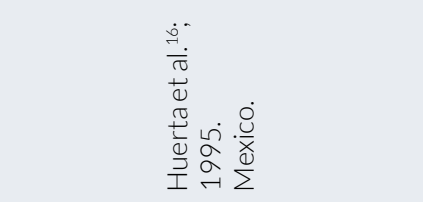 & 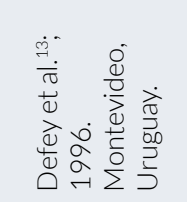 & 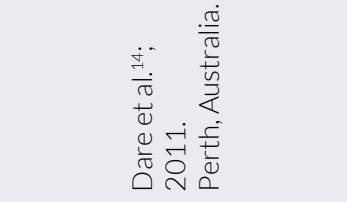 \\
\hline
\end{tabular}




\begin{tabular}{|c|c|c|c|c|}
\hline 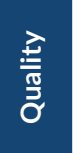 & $\begin{array}{l}0 \\
\stackrel{1}{\alpha} \\
\text { un } \\
0 \\
\text { z }\end{array}$ & 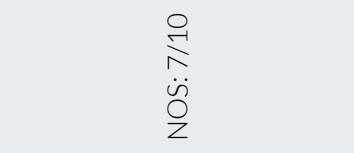 & $\begin{array}{l}\stackrel{0}{\overrightarrow{1}} \\
\stackrel{1}{0} \\
\stackrel{0}{z}\end{array}$ & 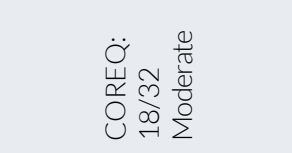 \\
\hline 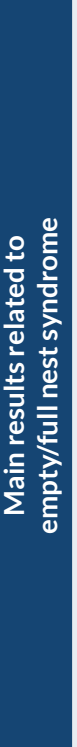 & 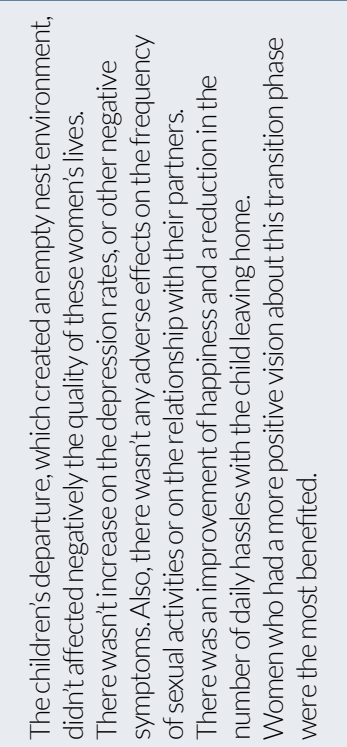 & 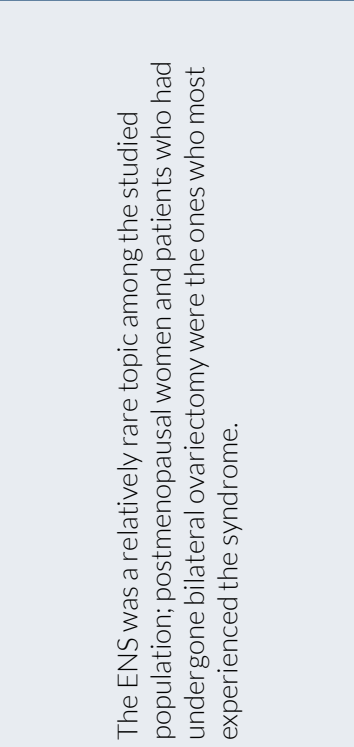 & 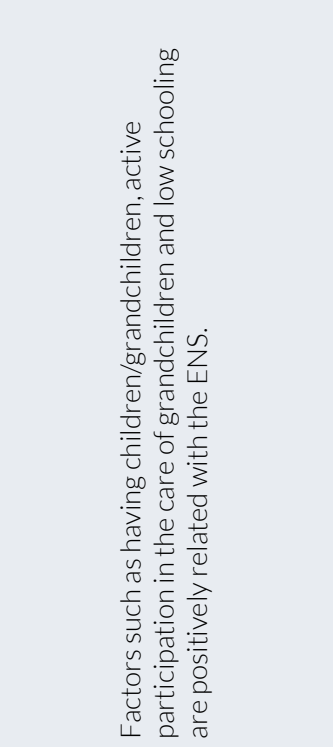 & 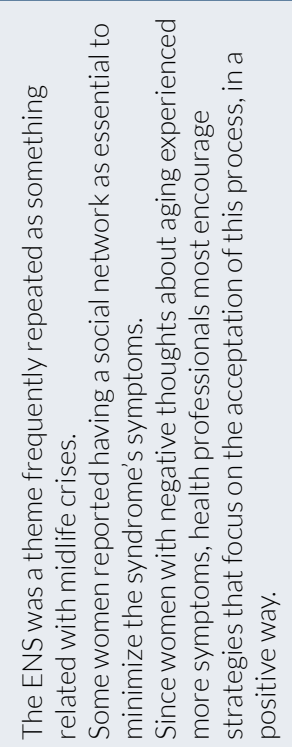 \\
\hline & 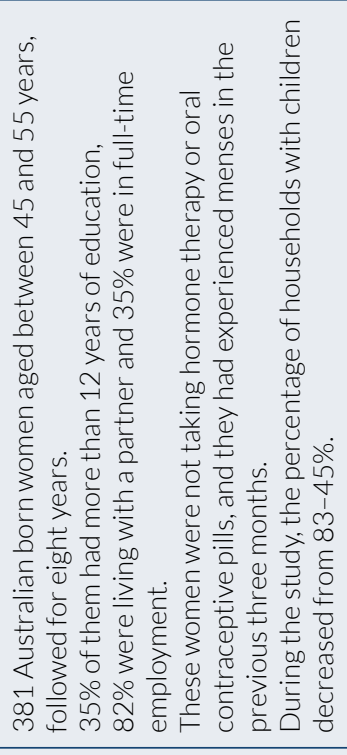 & 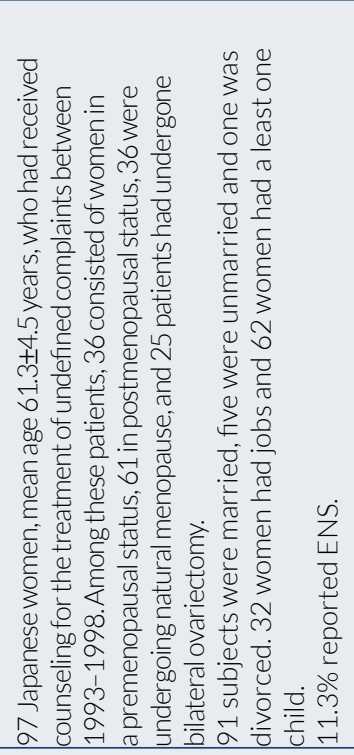 & 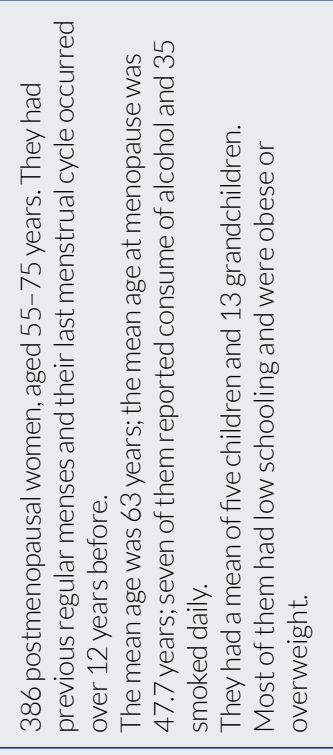 & 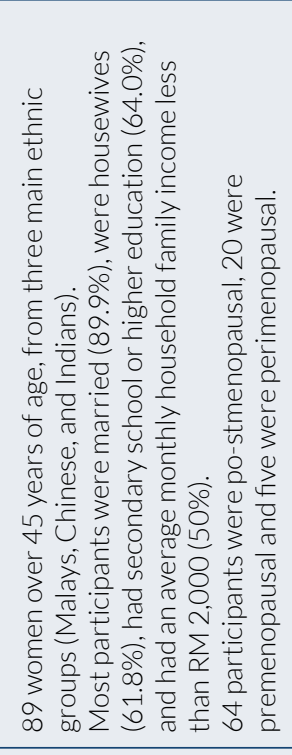 \\
\hline 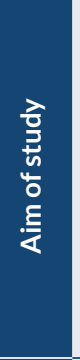 & 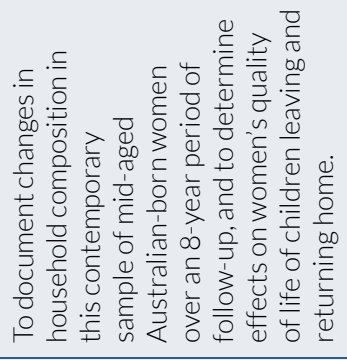 & 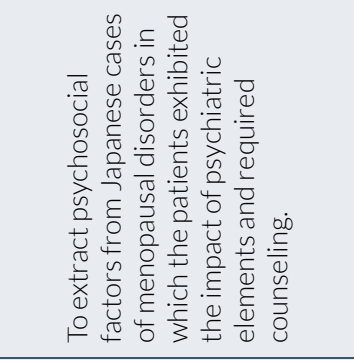 & 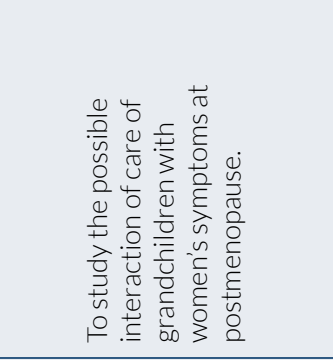 & 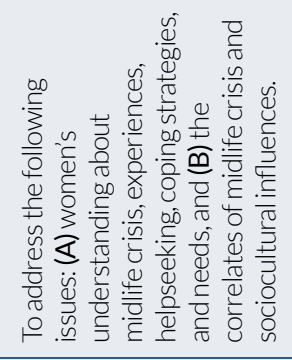 \\
\hline 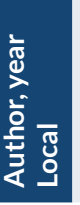 & 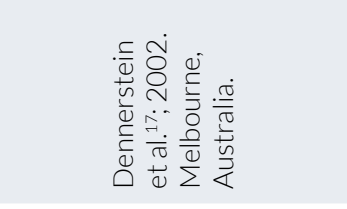 & 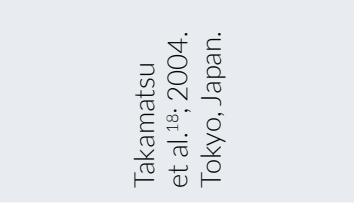 & 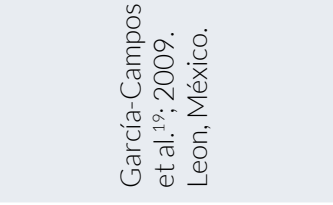 & 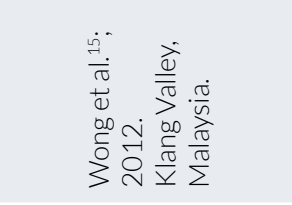 \\
\hline
\end{tabular}




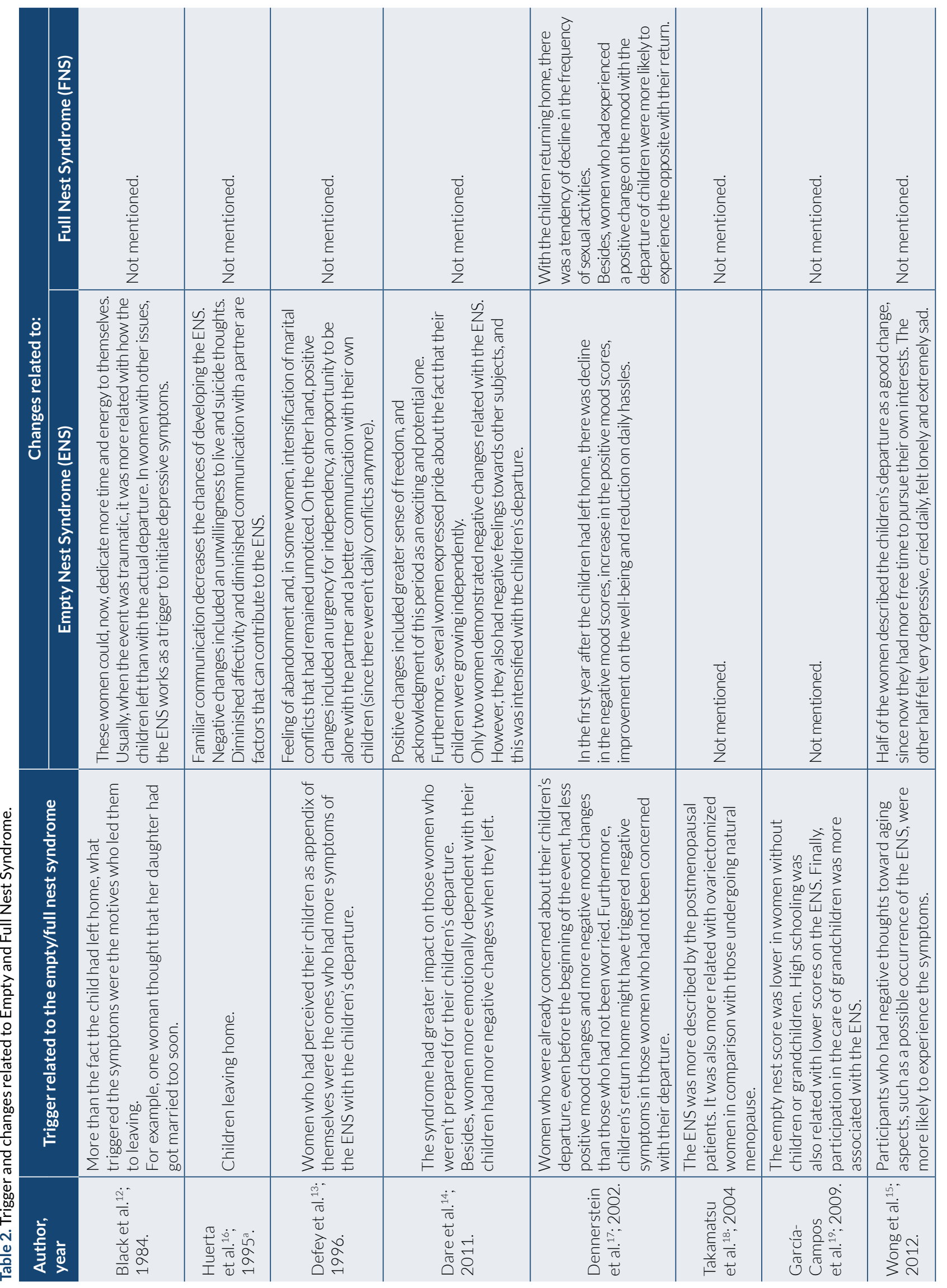




\section{DISCUSSION}

This systematic review makes it possible to orientate and distinguish factors related to FNS and ENS in the climacteric period.

Among the triggering factors of the ENS, the authors highlighted the dependent relationship between mothers and children and the anticipated concern about their children's departure ${ }^{13-15,17}$.

Wong et al. conducted a survey with three ethnic groups (i.e., Malaysian, Indian, and Chinese) and found that half of the women reported feeling sadness, emptiness, depression, and extreme loneliness ${ }^{15}$. The ENS was a theme frequently repeated as something related to midlife crises.

We can observe these same reports in the three other articles related to ENS, in which women whose children left home presented some emotional lability, as well as family conflicts, financial problems, physical changes, and decrease in social life $\mathrm{e}^{12,13,16}$. These characteristics are associated with the climacteric period, and these factors aggravate the feeling of loneliness and abandonment.

Huerta et al. demonstrated that diminished affectivity and communication with a partner are factors that can contribute to the ENS ${ }^{16}$. Negative changes included an unwillingness to live and suicidal thoughts. Good familiar communication decreased the chances of developing the ENS.

Garcia-Campos analyzed the relationship between taking care of grandchildren and the ENS ${ }^{19}$. They discovered that the higher frequency of meeting with, and helping in the care of, grandchildren correlates with scores of losses of sexual interest and was more associated with ENS.

The study by Polisseni et al. corroborates this finding as the authors pointed out that the family configuration in which there are children leaving home, grandchildren being born, and/or retirement facilitates the appearance of affective deprivation, feeling of uselessness, and fear of aging alone, the factors associated with ENS and their repercussions ${ }^{6}$. They estimated that one-third of women in the climacteric period will have at least one depressive episode and reported that hormonal and social changes corroborate concurrently in this period ${ }^{20}$.

The most common mood symptoms in this review in ENS were melancholy and sadness. Mitchell and Lovegreen described the presence of these feelings in the family configuration in which worried parents, with a greater sense of guilt, consider immature and nonautonomous children aggravating or causing the ENS ${ }^{7}$. In contrast, parents who feel that their children are self-sufficient have greater ease and tranquility in experiencing this social change. The authors also affirmed that women in the climacteric period with active social life present a lower appearance of feelings of sadness and melancholy after the children leave home.

Takamatsu et al. analyzed the psychosocial landscape of women in coping with menopausal symptoms, and what psychological issues were triggered ${ }^{18}$. Their difficult situations included problems with their husbands, children leaving home, anxiety, problems at work, difficulties with their mothers-in-law, and ENS in the postmenopausal period. Premenopausal anxiety was related to job reorganization or life difficulties, problems with coworkers, difficult relationship with husbands, and divorce were the issues more frequently present.

Wong et al., Takamatsu, et al., Defey et al., and GarciaCampos et al. investigated the ENS and found that depressive symptoms and lack of perspective of life improved with therapeutic or social groups ${ }^{13,15,18,19}$.

The therapeutic and social groups emphasize the resumption of some activities, which were abandoned due to the birth of the children, as a practice to be encouraged in the follow-up of women in the climacteric period ${ }^{15,18,21-23}$. In addition, Chen et al. reinforced that outdoor activities are the key point to reduce depressive symptoms, and those who are athletes, who participate in groups of conversation, or who have intense social interaction feel less need to be with their children daily and have less feeling of solitude ${ }^{24}$.

Dennerstein et al. conducted an 8-year follow-up study with 381 Australian women aged between 45 and 55 years to determine the effects on women's quality of life after children leave and return home ${ }^{17}$. They encountered that the children's departure, which created an empty nest environment, did not affect negatively the quality of these women's lives. Moreover, there was not an increase in the depression rates or other negative symptoms and no adverse effects on the frequency of sexual activities or on the relationship with their partners.

In the studies developed by Defey et al., Dare, and Wong et al., positive changes were also reported with children leaving home $\mathrm{e}^{13-15}$. They reported that the women experienced an opportunity to be alone with the partner and a better communication with their own children (since there were no daily conflicts anymore); there was also a decline in the negative mood scores, increase in the positive mood scores, improvement on the well-being, and more free time to pursue their own interests.

The study conducted by Dennerstein et al. was the only study that addressed the FNS and found that when children return home, there was a tendency of decline in the frequency of sexual activities ${ }^{17}$. Besides, women who had 
experienced a positive change in the mood with the departure of children were more likely to experience the opposite with their return.

The FNS, contextualized by Rambo et al., has factors related to the permanence of the young adult in parents' house, "kangaroo generation", the increase of schooling time, difficult insertion in the labor market, and economic dependence ${ }^{4}$. Silveira and Wagner and Vieira and Rava reported about the children of the "kangaroo generation" and their parents and found that the main factor associated with the emergence of this context in FNS is the lack of professional perspective of the child or the lack of job opportunity and maintenance of financial independence ${ }^{25,26}$.

In addition, the children also seek salaries commensurate with their qualifications and specializations, not content with the first job that offers them independence. All these contexts corroborate with the appearance of the FNS.

Unfortunately, in our systematic review, few authors reported details on the socioeconomic level of the children or dependents of their participants or cases. Thus, we emphasized the importance of encouraging studies with quality criteria about the topic FNS.

Weber et al. explained that indulgent parents are responsive but not demanding, i.e., they have respect for their children and at the same time do not stimulate the autonomous development of the child because they are always performing tasks for them ${ }^{27}$. As a result, children grow up with a sense of dependence on their parents and mistakenly believe that they will not be able to develop on their own. It is the role of the parents to stimulate this autonomy at an early age, always demonstrating that they will be around to help in difficult times.

Garcia-Campos, Defey et al., Takamatsu et al., and Wong et al. mentioned triggering factors related to biological, familial, social, and, more rarely, financial aspects ${ }^{13,15,18,19}$. The economic factor is present regarding the appearance of the two syndromes. In FNS, women are in a phase of life that should be directed toward their biopsychosocial changes, as well as rest, and they are faced with their children without financial autonomy. In contrast, in the ENS, the woman shows fragility after the independence of her loved ones.

Factors that trigger changes are present in the lives of these women. This aspect was evidenced in the results presented in several studies, highlighting the positive factors related to women's autonomy, time available to themselves, and family life ${ }^{12-15,17,19}$.

The negative symptoms (i.e., sadness, anxiety, and fear) were mainly related to somatic changes, highlighting body changes, issues related to attractiveness, and work performance as main triggers $^{12-19}$. In addition, Garcia-Campos et al. reported that the responsibility to take care of grandchildren, divorce, and lack of social interaction were associated with loss of sexual interest and couple conflicts ${ }^{19}$. All these triggering factors should be considered by health professionals who assist women during the climacteric period and late postmenopausal period since these aspects interfere in several dimensions and aspects in the life and health of women.

A limiting factor for this study was the lack of specific health descriptors for these subjects. In addition, the literature presents a shortage of clinical research focused on the new context of the family nucleus related to FNS.

The use of the CORE-Q checklist and NOS in this study brings the importance of systematizing work processes in qualitative and quantitative research that should follow methodological quality criteria, in order to allow evaluation and analysis to elucidate nonbiophysical and fundamental aspects in clinical practice.

The novelty of this review is that the emergence of FNS and ENS during the climacteric period presents the socioeconomic context as the main trigger, associated with the biological and cultural specificities of each woman.

The emotional conflict present in both syndromes is a factor that points to the financial dependence of the children and the permanence of the children in the parents' home, or even the internal conflict that occurs in the woman, often related to her financial dependence.

We propose a discussion about how both syndromes should have a multi-professional approach. In relation to FNS, the proposal of multi-professional and intersectoral intervention as social support should include the family, stimulating the autonomy and independence of the children.

The negative changes associated with ENS and FNS were depressive mood, depression, lack of time for self-care, and lack of sexual interest and attractiveness. In contrast, the main positive aspects were the feeling of autonomy and familiar coexistence. All these data are noticed during the care of women in the climacteric period and in the postmenopausal period of life, being fundamentally structured within the FNS and ENS.

Therefore, regarding the ENS, the focus of health care intervention should be on the women, stimulating their autonomy and reducing possible psychological dependencies that make them want their children always close by.

\section{CONCLUSIONS}

The factors related to the ENS demonstrated in the review were the woman's condition of having children and financial 
dependence, whereas the low socioeconomic level stood out in the FNS. The trigger of symptoms related to the ENS and FNS was mainly related to body changes caused by hypoestrogenism and social aspects. The negative changes associated with ENS and FNS were depressed mood, depression, lack of time for self-care, and lack of sexual interest and attractiveness. In contrast, the main positive aspects were the feeling of autonomy and familiar coexistence.

\section{ACKNOWLEDGMENT}

The authors thank Cristiane Dolores Barboza de Oliveira and Ana Carolina Fonseca for their contributions to this project.

\section{REFERENCES}

1. Taechakraichana N, Jaisamrarn U, Panyakhamlerd K, Chaikittisilpa S, Limpaphayom KK. Climacteric: concept, consequence and care. J Med Assoc Thai. 2002;8544(Suppl 1):S1-15. PMID: 12188398

2. Barber CE. Transition to the empty nest. In: Bahr SJ, Peterson ET (editors). Aging and the family. Lanham: Lexington Books; 1989. p.15-32.

3. Liang Y, Wu W. Exploratory analysis of health-related quality of life among the empty-nest elderly in rural China: an empirical study in three economically developed cities in eastern China. Health Qual Life Outcomes. 2014;12:59. https://doi.org/10.1186/14777525-12-59

4. Rambo M, Hentges CE, Löeblein FG, Pando LB, Klockner MIB, Bertoldo LTM. Uma nova configuração familiar. Perspectivas em Psicologia. 2018;22(1):168-79. https://doi.org/10.14393/ PPv22n1a2018-12

5. Copeland JR, Beekman AT, Braam AW, Dewey ME, Delespaul P, Fuhrer R, et al. Depression among older people in Europe: the EURODEP studies. World Psychiatry. 2004;3(1):45-9. PMID: 16633454

6. Polisseni AF, Araújo DA, Polisseni F, Mourão Junior CA, Polisseni J, Fernandes ES, etal. Depressão eansiedadeem mulheres climatéricas: fatores associados. Rev Bras Ginecol Obstet. 2009;31(1):28-34. https://doi.org/10.1590/s0100-72032009000100006

7. Mitchell BA, Lovegreen LD. (2009). The empty nest syndrome in midlife families: a multimethod exploration of parental gender differences and cultural dynamics. J Fam Issues. 30(12):1651-70. https://doi.org/10.1177/0192513X09339020

8. Moher D, Liberati A, Tetzlaff J, Altman DG, PRISMA Group. Preferred reporting items for systematic reviews and metaanalyses: the PRISMA statement. BMJ. 2009;339:b2535. https:// doi.org/10.1136/bmj.b2535

9. Hermont AP, Oliveira PAD, Martins CC, Paiva SM, Pordeus IA, Auad SM. Quality assessment criteria used for cross-sectional studies through a modified version of Newcastle-Ottawa Scale for observational studies. PLoS ONE Dataset. 2014;9:e111123. https://doi.org/10.1371/journal.pone.0111123.t002

10. Welss GA, Shea B, O'Connell D, Peterson J, Welch V, Losos M, et al. The Newcastle-Ottawa Scale (NOS) for assessing the quality of nonrandomised studies in meta-analyses. Ottawa: Institute OHR; 2009.

\section{AUTHORS' CONTRIBUTIONS}

ACGA: Conceptualization, Data curation, Investigation, Project administration, Visualization, Writing - review \& editing. MSA: Conceptualization, Data curation, Investigation, Project administration, Visualization, Writing - review \& editing. LTSZ: Methodology, Validation, Visualization, Writing - review \& editing. SVS: Methodology, Validation, Visualization, Writing - review \& editing. PRSN: Data curation, Formal analysis, Methodology, Supervision, Writing - review \& editing. ECB: Conceptualization, Project administration, Supervision, and Visualization. JMSJ: Formal Analysis, Project administration, Writing - review \& editing. ICES: Conceptualization, Data curation, Methodology, Project administration, Supervision, Validation, Visualization

11. Tong A, Sainsbury P, Craig J. Consolidated criteria for reporting qualitative research (COREQ): a 32-item checklist for interviews and focus groups. Int J Qual Health Care. 2007;19(6):349-57. https://doi.org/10.1093/intahc/mzm042

12. Black SM, Hill CE. The psychological well-being of women in their middle years. Psychol Women Q.1984;8(3): 282-92. https://doi. org/10.1111/j.1471-6402.1984.tb00637.x

13. Defey D, Storch E, Cardozo S, Díaz O, Fernández G. The menopause: women's psychologyand healthcare. Soc SciMed. 1996;42(10):144756. https://doi.org/10.1016/0277-9536(95)00344-4

14. Dare JS. Transitions in midlife women's lives: contemporary experiences. Health Care Women Int. 2011;32(2):111-33. https:// doi.org/10.1080/07399332.2010.500753

15. Wong LP, Awang H, Jani R. Midlife crisis perceptions, experiences, help-seeking, and needs among multi-ethnic malaysian women. Women Health. 2012;52(8):804-19. https://doi.org/10.1080/0 3630242.2012.729557

16. Huerta R, Mena A, Malacara JM, León JD. Symptoms at perimenopausal period: its association with attitudes toward sexuality, life-style, family function, and FSH levels. Psychoneuroendocrinology. 1995;20(2):135-48. https://doi. org/10.1016/0306-4530(94)00046-d

17. Dennerstein L, Dudley E, Guthrie J. Empty nest or revolving door? A prospective study of women's quality of life in midlife during the phase of children leaving and re-entering the home. Psychol Med. 2002;32(3):545-50.https://doi.org/10.1017/s0033291701004810

18. Takamatsu K, Makita K, Nozawa S. Study of psychosocial factors in Japanese patients suffering from menopausal disorders. J Obstet Gynaecol Res. 2004;30(4):309-15. https://doi.org/10.1111/j.14470756.2004.00199.x

19. García-Campos R, Aguilar-Zavala H, Malacara JM. Symptoms at menopause and care of grandchildren. Climacteric. 2010;13(5):492-8. https://doi.org/10.3109/13697130903411107

20. Stotland NL. Menopause: social expectations, women's realities. ArchWomens Ment Health. 2002;5(1):5-8.https://doi.org/10.1007/ s007370200016

21. Helson R, Wink P. Personality change in women from the early 40s to the early 50s. Psychol Aging. 1992;7(1):46-55. https://doi. org/10.1037//0882-7974.7.1.46

22. Sorpreso ICE, Vieira LHL, Calió CL, Haidar MA, Baracat EC, Soares Junior JM. Health education intervention in early and late 
postmenopausal Brazilian women. Climacteric. 2012;15(6):573-

80. https://doi.org/10.3109/13697137.2011.635915

23. Sorpreso IC, Soares Júnior JM, Fonseca AM, Baracat EC. Female aging. Rev Assoc Med Bras (1992). 2015;61(6):553-6. https://doi. org/10.1590/1806-9282.61.06.553

24. Chen D, Yang X, Aagard SD. The empty nest syndrome: ways to enhance quality of life. Educ Gerontol. 2012;38(8):520-9. https:// doi.org/10.1080/03601277.2011.595285
25. Silveira PG, Wagner A. Ninho cheio: a permanência do adulto jovem em sua família de origem. Estud Psicol (Campinas). 2006;23(4):441 53. https://doi.org/10.1590/S0103-166X2006000400012

26. Vieira ACS, Rava PGS. Ninho cheio: perspectivas de pais e filhos. Psicol Teor prat. 2012;14(1):84-96.

27. Weber LND, Prado PM, Viezzer AP, Viezzer AP, Brandenburg OJ. Identificação de estilos parentais: o ponto de vista dos pais e dos filhos. Psicol Reflex Crit. 2004;17(3):323-31. https://doi. org/10.1590/S0102-79722004000300005

Appendix 1. Research strategy.

\begin{tabular}{|c|c|c|}
\hline Base & Query & Number of articles \\
\hline Pubmed & $\begin{array}{l}\text { ("Menopause"[Mesh] OR "Menopause, Premature"[Mesh] OR "Postmenopause"[Mesh] OR } \\
\text { "Premenopause"[Mesh] OR "Climacteric"[Mesh]) AND (Empty nest OR Full nest) }\end{array}$ & 14 \\
\hline Embase & $\begin{array}{l}\text { ('menopause and climacterium'/exp OR 'menopause'/exp OR 'climacterium'/exp OR 'postmenopause'/ } \\
\text { exp OR 'premenopause'/exp) AND ('empty nest' OR 'full nest') }\end{array}$ & 24 \\
\hline $\begin{array}{l}\text { Web of } \\
\text { Science }\end{array}$ & $\begin{array}{l}\text { (TÓPICO: ( }{ }^{*} \text { menopaus*) OR TÓPICO: (climacteri*)) AND } \\
\text { (TÓPICO: (Full nest) OR TÓPICO: (Empty nest)) }\end{array}$ & 43 \\
\hline Psyclnfo & $\begin{array}{l}\text { ((IndexTermsFilt: (“Menopause”)) OR (Any Field: (climacteric)) OR (Any Field: ("menopaus*))) AND } \\
\text { ((Any Field: (Full Nest)) OR (Any Field: (Empty nest))) }\end{array}$ & 21 \\
\hline
\end{tabular}

